Check for updates

Cite this: RSC Adv., 2019, 9, 3838

Received 25th November 2018 Accepted 23rd January 2019

DOI: $10.1039 / \mathrm{c} 8 \mathrm{ra09695c}$

rsc.li/rsc-advances

\section{Novel sulfonated poly(ether ether ketone)/ triphenylamine hybrid membrane for vanadium redox flow battery applications}

\author{
Yizhou Quan, (D) Gang Wang, ${ }^{*}$ Anfeng Li, Xiaoyan Wei, Feng Li, Jie Zhang, \\ Jinwei Chen and Ruilin Wang*
}

\begin{abstract}
A novel sulfonated poly(ether ether ketone)/triphenylamine hybrid membrane with various triphenylamine loadings ( $1 \%, 2 \%$ and $5 \%$ ) has been successfully fabricated. Optimum triphenylamine loading was confirmed by exploring the physicochemical properties and morphology of different membranes. The hybrid membrane exhibited lower vanadium permeability than pristine SPEEK membranes due to the acid-base interaction between amine groups and sulfonated groups. Introduction of triphenylamine also improved the proton conductivity because the nitrogen atom of triphenylamine can be protonated and contribute to the proton transfer. As the result, the hybrid membrane demonstrated higher ion selectivity compared with SPEEK and Nafion115 membranes. The VRFB single cell with SPEEK/TPAM-1\% membrane showed better performance compared to a Nafion115 membrane at the current density of $60 \mathrm{~mA} \mathrm{~cm}^{-2}$. The SPEEK/TPAM hybrid membrane has great potential for VRFB application.
\end{abstract}

\section{Introduction}

As a large-scale energy storage technology, the redox flow battery (RFB) has unique characteristics, such as long cycle-life, high efficiency and environmental friendliness. ${ }^{1-3}$ Among various types of RFB technologies, the vanadium redox flow battery (VRFB) uses the same material in both half-cells, which avoids cross-contamination of the two half-cells' electrolytes and provides the electrolytes with potentially unlimited life. Therefore, it is especially suited for large stationary energy storage. ${ }^{4}$ VRFBs include two electrolyte tanks and a battery stack. V(II)/V(III) and V(IV)/V(v) couples in sulfuric acid solution are used as negative and positive electrolytes, respectively, which cyclically pump in the stacks. ${ }^{5}$

The proton exchange membrane (PEM) is a key part of a VRFB, it prevents positive and negative half-cells from crossmixing, and meanwhile, it needs to transport chargebalancing ions, such as $\mathrm{H}^{+}, \mathrm{SO}_{4}{ }^{2-}$ and $\mathrm{HSO}_{4}{ }^{-}{ }^{6,7}$ The properties of PEM determine the performance of VRFB, so that the ideal PEM is required to possess better chemical stability, high ion selectivity, low cost and excellent mechanical strength. ${ }^{8,9}$ The most commonly used commercial membrane is Dupont's Nafion ${ }^{\circledR}$ membrane, which exhibits high proton conductivity and outstanding chemical stability ${ }^{10}$ However, high price and high vanadium permeability limit its further application. ${ }^{11}$ Therefore, the alternative PEM of VRFB needs to be explored.

College of Materials Science and Engineering, Sichuan University, Chengdu 610065, China. E-mail: electrowg100@scu.edu.cn; rlwang@scu.edu.cn; Fax: +86 2885418018; Tel: +862885418018
To this day, fluorinated ${ }^{12,13}$ and non-perfluorinated membranes have been comprehensively developed, such as sulfonated poly(ether ether ketone) (SPEEK), ${ }^{14-17}$ sulfonated poly (diallyl-bisphenol ether ether ketone) (SDPEEK), ${ }^{18}$ sulfonated polyimide (SPI), ${ }^{19}$ polybenzimidazole (PBI) ${ }^{20}$ and sulfonated polysulfone (SPSF). ${ }^{21}$ Among these sulfonated aromatic polymers, SPEEK has been widely used in VRFB owing to its high ion selectivity, easy preparation and low cost. ${ }^{22}$ Nevertheless, the performance of SPEEK is greatly affected by the degree of sulfonation (DS). ${ }^{23}$ So researchers turn their attention to modify SPEEK to satisfy both high conductivity and low swelling ratio. In recent years, many methods of PEM modification have been reported, such as filling with inorganic particles like $\mathrm{TiO}_{2}$ and $\mathrm{SiO}_{2},{ }^{24-27}$ blending polymers like PAN and $\mathrm{PVDF},{ }^{28,29}$ doping organic fillers ${ }^{30,31}$ and multilayer protection. ${ }^{32,33}$ Introducing the amine functional group to achieve acid-base blend membrane is the most frequently used strategy to modify the SPEEK membranes. Xi et al. coated the SPEEK with polydopamine to protect the membranes from being corroded by the strong acidic and oxidizing environment. ${ }^{34}$ Besides, Yan et al. used imidazolium-functionalized polysulfone as the base polymer and SPEEK as the acid polymer to prepare the amphoteric membrane for VRFB, which showed both higher coulombic efficiency and energy efficiency than Nafion 212 membrane. ${ }^{35}$

The triphenylamine(TPAM) unit has been widely studied and applied in various optoelectronic materials and organic field effect transistors. ${ }^{36}$ It is a great electron donor unit ${ }^{37}$ and the nitrogen atom of TPAM can be protonated and functioned as an ion exchange site to improved proton conductivity. ${ }^{38}$ Furthermore, the acid-base interactions in the acid-base polymer 
blend membrane could decrease the swelling degree and the electrolyte corrosion, and improve the vanadium ions resistance and selectivity. ${ }^{39}$

Our group has been working on the membrane of VRFB for many years, such as the surface modification of Nafion membrane ${ }^{40}$ the optimization and composite of SPEEK. ${ }^{41,42}$ Therefore, based on the above facts, we selected TPAM for modification and doping of SPEEK and prepared a novel SPEEK/ TPAM hybrid membrane. The properties and corresponding VRFB cell performance of the hybrid membrane were investigated.

\section{Experimental}

\subsection{Materials}

Poly(ether ether ketone) (PEEK) (Victrex, PEEK 450PF) was dried under vacuum at $100^{\circ} \mathrm{C}$ for $24 \mathrm{~h}$. The Nafion 115 membrane was purchased from DuPont Company, Nafion115 membrane was treated by $3 \mathrm{wt} \% \mathrm{H}_{2} \mathrm{O}_{2}$ solution at $80{ }^{\circ} \mathrm{C}$ for $1 \mathrm{~h}$, deionized water at $80{ }^{\circ} \mathrm{C}$ for $30 \mathrm{~min}$ and $1 \mathrm{~mol} \mathrm{~L}^{-1} \mathrm{H}_{2} \mathrm{SO}_{4}$ solution at $80{ }^{\circ} \mathrm{C}$ for $30 \mathrm{~min}$. All the other reagents were provided by local chemical suppliers and used without further purification, including TPAM, $N, N$-dimethylacetamide (DMAC), $\mathrm{H}_{2} \mathrm{SO}_{4}$ (98 wt\%), $\mathrm{NaCl}$, $\mathrm{NaOH}, \mathrm{VOSO}_{4}$ and $\mathrm{MgSO}_{4} \cdot 7 \mathrm{H}_{2} \mathrm{O}$.

\subsection{Preparation of SPEEK/TPAM membrane}

$5 \mathrm{~g}$ PEEK was added into $100 \mathrm{~mL} \mathrm{H}_{2} \mathrm{SO}_{4}(98 \mathrm{wt} \%)$ and the reactants were stirred at $45{ }^{\circ} \mathrm{C}$ for $4.5 \mathrm{~h}$. Then the solution was poured into excess ice-cold water to terminate the sulfonated reaction. The SPEEK was washed until the $\mathrm{pH}$ reached neutrality, and dried under vacuum at $100{ }^{\circ} \mathrm{C}$ for $12 \mathrm{~h}$. The DS of SPEEK was 55\% determined by titration method. ${ }^{43}$ The SPEEK/TPAM membrane was made by the traditional solution casting method. ${ }^{23} 1.5 \mathrm{~g}$ SPEEK was dissolved into $10 \mathrm{~mL}$ DMAC and the TPAM was dissolved into the solution. The membrane was cast by pouring the solution on a stainless plate and dried at $80^{\circ} \mathrm{C}$ for $10 \mathrm{~h}$ and $100{ }^{\circ} \mathrm{C}$ for $8 \mathrm{~h}$. Then the membrane was soaked in $1 \mathrm{~mol} \mathrm{~L}^{-1} \mathrm{H}_{2} \mathrm{SO}_{4}$ solution for $24 \mathrm{~h}$, and stored in deionized water before use.

\subsection{Membrane characterization}

2.3.1 Membrane morphology and thermogravimetric analysis. The surface and cross-section morphology of various membrane were analyzed by scanning electron microscope (FESEM, Hitachi S4800, Japan). X-ray photoelectron spectroscopy (XPS) was used to analyze the surface chemical composition of the S/TPAM membrane. Thermogravimetric analysis (TGA, NETZSCH STA 449 C) was used to investigate the thermal properties of SPEEK and SPEEK/TPAM membrane. The sample was heated at $20{ }^{\circ} \mathrm{C} \mathrm{min}{ }^{-1}$ from room temperature to $800{ }^{\circ} \mathrm{C}$ under argon atmosphere.

2.3.2 Water uptake and swelling ratio. The weight and length of the wet membrane were quickly measured after wiping off excess water on the surface. After $24 \mathrm{~h}$ of drying in the vacuum oven at $100^{\circ} \mathrm{C}$, the weight and length of the membrane were measured. Water uptake $\left(W_{\mathrm{U}}\right)$ and swelling ratio $\left(S_{\mathrm{R}}\right)$ were evaluated according to the formulas (1) and (2):

$$
W_{\mathrm{U}}=\frac{W_{\text {wet }}-W_{\text {dry }}}{W_{\text {dry }}} \times 100 \%
$$

where $W_{\text {wet }}$ and $W_{\text {dry }}$ are the weights of wet and dry membranes, respectively.

$$
S_{\mathrm{R}}=\frac{L_{\mathrm{wet}}-L_{\mathrm{dry}}}{L_{\mathrm{dry}}} \times 100 \%
$$

where $L_{\mathrm{wet}}$ and $L_{\mathrm{dry}}$ are the lengths of wet and dry membranes, respectively.

2.3.3 Ion exchange capacity (IEC) and proton conductivity. IEC of the membrane was evaluated by the conventional titration method. ${ }^{43}$ The sample was soaked in $50 \mathrm{~mL}$ of $1 \mathrm{~mol} \mathrm{~L}^{-1}$ $\mathrm{NaCl}$ for $24 \mathrm{~h}$, to make the $\mathrm{Na}^{+}$and $\mathrm{H}^{+}$exchange. The resultant solution was titrated with $0.01 \mathrm{~mol} \mathrm{~L}^{-1} \mathrm{NaOH}$, using phenolphthalein as indicator. IEC was evaluated according to the formula:

$$
\operatorname{IEC}\left(\mathrm{mmol} \mathrm{g}^{-1}\right)=\frac{C_{\mathrm{NaOH}} \times V_{\mathrm{NaOH}}}{W_{\mathrm{dry}}}
$$

where $V_{\mathrm{NaOH}}$ is the volume of consumed $\mathrm{NaOH}$ solution and $C_{\mathrm{NaOH}}$ is the concentration of $\mathrm{NaOH}$ solution.

The proton conductivity of the membrane was measured by electrochemical impedance spectroscopy (EIS), using a Solartron $1287+1260$ electrochemical station (USA, AMETEK, Inc.). The proton conductivity was evaluated according to the formula:

$$
\sigma\left(\mathrm{S} \mathrm{cm}^{-1}\right)=\frac{L}{A \times R}
$$

where $A$ and $L$ are the effective area and thickness of the sample membrane, and $R$ is the sample membrane resistance.

2.3.4 $\mathrm{VO}^{2+}$ permeability and selectivity. The method of $\mathrm{VO}^{2+}$ ion permeability test was described by the previous literature. ${ }^{29}$ The left reservoir was filled with $25 \mathrm{~mL}$ of $1 \mathrm{M} \mathrm{VOSO}_{4}$ (the concentration of the vanadium ions in the electrolyte were measured by 916 Ti-Touch (Metrohm) potentiometric titrator) in $3 \mathrm{M} \mathrm{H}_{2} \mathrm{SO}_{4}$ solution, and $25 \mathrm{~mL}$ of $1 \mathrm{M} \mathrm{MgSO}_{4}$ in $3 \mathrm{M} \mathrm{H}_{2} \mathrm{SO}_{4}$ solution was on the right to minimize the effect of osmotic pressure. The sample from the right side was taken out every $1 \mathrm{~h}$ to measure the concentration of $\mathrm{VO}^{2+}$ by a UV-vis spectrometer (TU-1900, China). The $\mathrm{VO}^{2+}$ permeability of the membrane was evaluated according to the formula:

$$
V_{\mathrm{R}} \frac{\mathrm{d} C_{\mathrm{R}}(t)}{\mathrm{d} t}=A \frac{P}{L}\left(C_{\mathrm{L}}-C_{\mathrm{R}}(t)\right)
$$

where $V_{\mathrm{R}}$ is the solution volume of the right reservoir, $C_{\mathrm{L}}$ and $C_{\mathrm{R}}(t)$ are the $\mathrm{VO}^{2+}$ concentration in the left and right reservoirs respectively, $A$ and $L$ are the effective area and thickness of the sample membranes respectively, $P$ is the $\mathrm{VO}^{2+}$ permeability. ${ }^{44}$

Ion selectivity $(S)$ of the membrane was defined as the ratio of proton conductivity over $\mathrm{VO}^{2+}$ permeability, and it was evaluated according to the formula:

$$
S=\frac{\sigma}{P}
$$




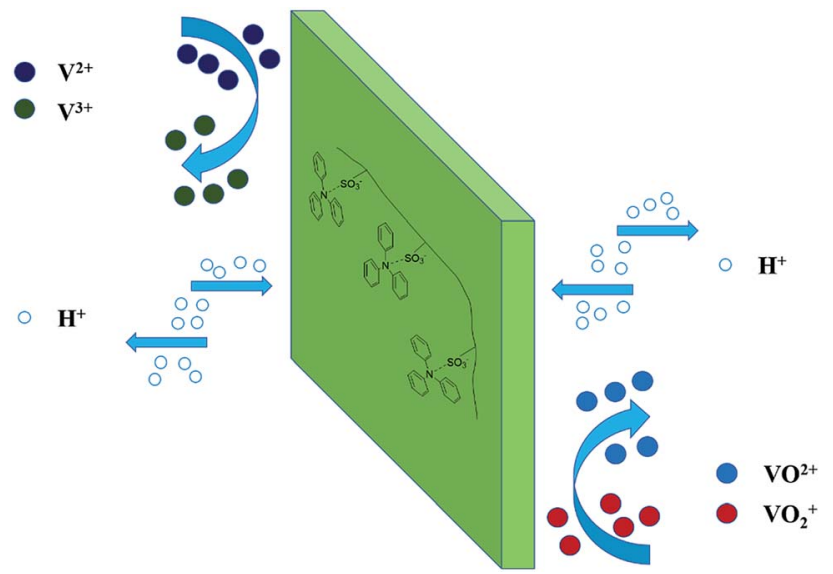

Fig. 1 Proposed mechanism for proton transportation and vanadium ion permeation process in SPEEK/TPAM hybrid membrane.

\subsection{VRFB single cell test}

The VRFB single cell was assembled by sandwiching a membrane with $5 \mathrm{~cm} \times 5 \mathrm{~cm}$ effective area, using two pieces of $5 \mathrm{~mm}$ thickness graphite felt as electrodes, and two graphite polar plates and two copper foils as current collectors. $40 \mathrm{~mL}$ of $1.5 \mathrm{~mol} \mathrm{~L}^{-1} \mathrm{~V}^{3.5+}$ in $3 \mathrm{~mol} \mathrm{H}_{2} \mathrm{SO}_{4}$ solution acted as the positive and negative electrolyte, respectively. Both of the electrolytes were cycled by the peristaltic pump (BT100L, LEAD FLUID, China) and the flow rate was set at $39 \mathrm{~mL} \mathrm{~min}^{-1}$. The cell was tested by a Land-CT2001A battery test system (Wuhan Land Co.
Ltd.) with the current density of $60 \mathrm{~mA} \mathrm{~cm}^{-2}, 1.65 \mathrm{~V}$ was the upper limit of charge voltage and $0.8 \mathrm{~V}$ was the lower limit of the charge voltage to avoid the corrosion of electrodes. The coulombic efficiency (CE), voltage efficiency (VE) and energy efficiency (EE) of the cell were calculated by formula (7)-(9):

$$
\begin{gathered}
\mathrm{CE}=\frac{\int I_{\mathrm{d}} \mathrm{d} t}{\int I_{\mathrm{c}} \mathrm{d} t} \times 100 \% \\
\mathrm{VE}=\frac{\int V_{\mathrm{d}} I_{\mathrm{d}} \mathrm{d} t}{\int V_{\mathrm{c}} I_{\mathrm{c}} \mathrm{d} t} \times 100 \% \\
\mathrm{VE}=\frac{\mathrm{EE}}{\mathrm{CE}} \times 100 \%
\end{gathered}
$$

where $I_{\mathrm{c}}$ and $I_{\mathrm{d}}$ are the charge and discharge current, respectively; and $V_{\mathrm{c}}$ and $V_{\mathrm{d}}$ are the charge and discharge voltage, respectively.

\subsection{Chemical stability}

Chemical stability was detected by soaking the membranes in $30 \mathrm{~mL}$ of $1.5 \mathrm{~mol} \mathrm{~L}^{-1} \mathrm{VO}_{2}^{+}$with $3 \mathrm{~mol} \mathrm{~L}^{-1}$ sulfuric acid for 30 days. And the weight loss of the membranes was calculated by formula (10).

$$
\text { Weight loss }=\frac{W_{0}-W}{W_{0}} \times 100 \%
$$

where $W_{0}$ and $W$ are the membrane weight before and after soaking into $\mathrm{V}(\mathrm{v})$ solution for 30 days.

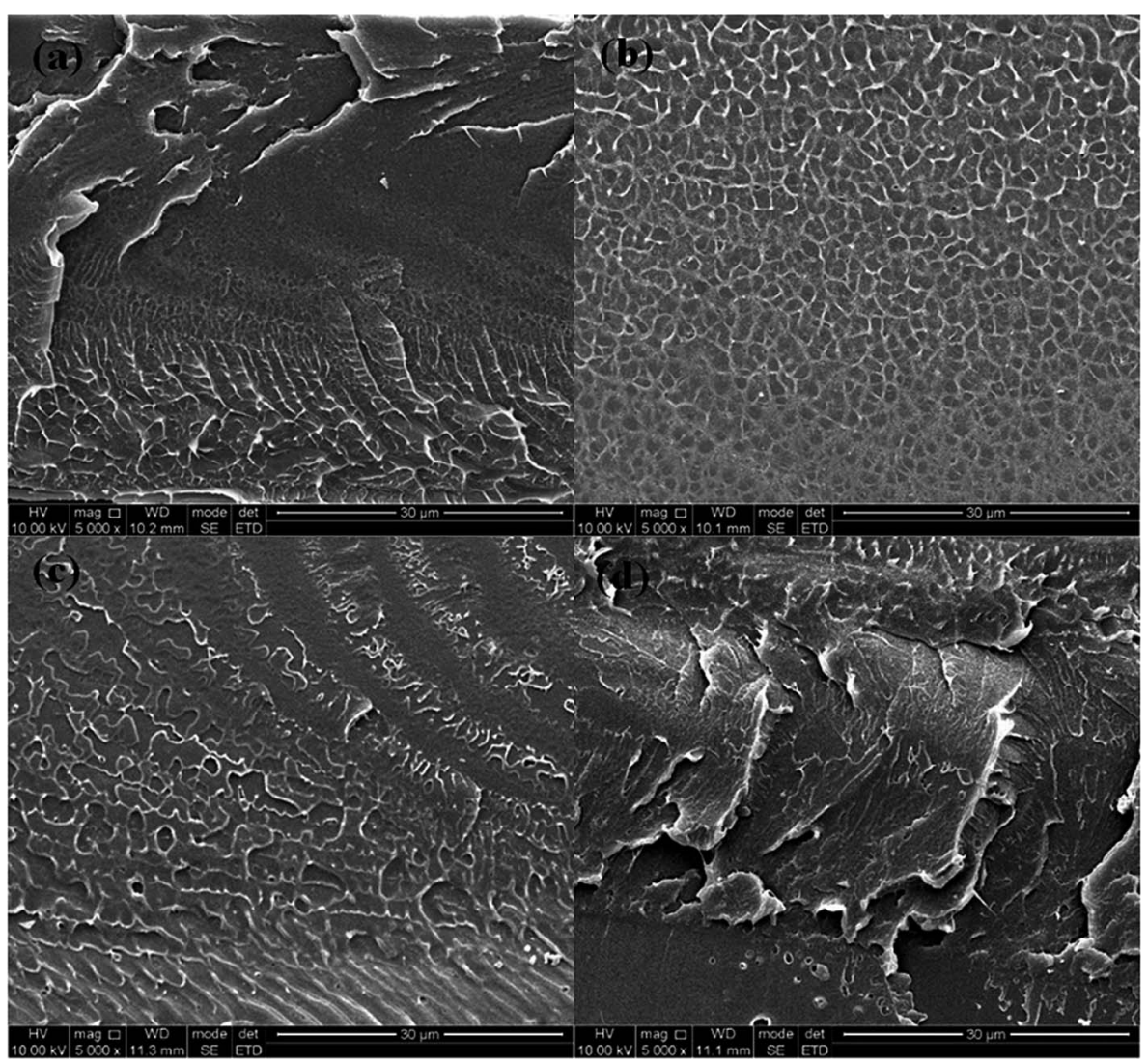

Fig. 2 SEM images of the cross-section morphology of the SPEEK (a), S/TPAM-1\% (b), S/TPAM-2\% (c) and S/TPAM-5\% (d). 


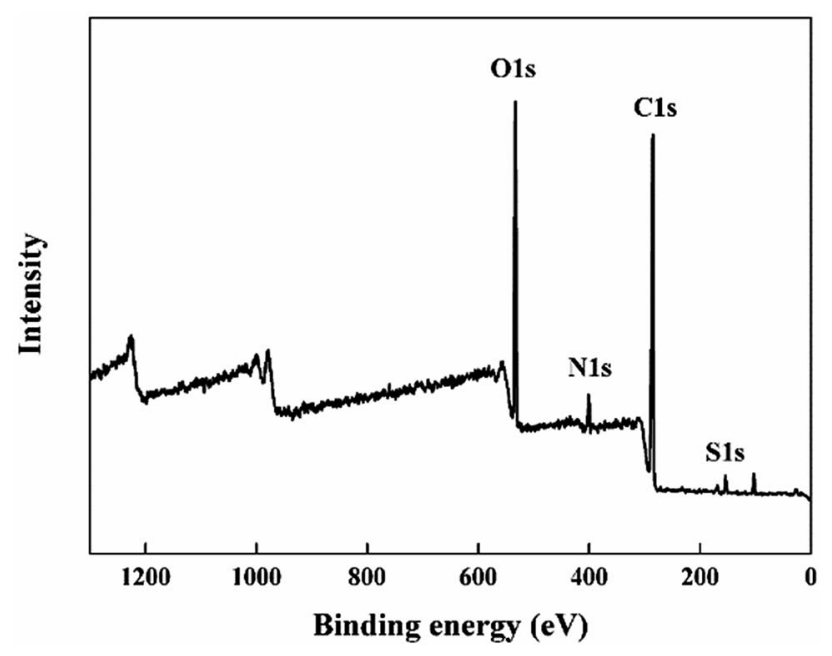

Fig. 3 XPS spectra of the S/TPA-1\% membrane.

\section{Result and discussion}

\subsection{SEM and XPS characterizations}

SPEEK was firstly hybrid with the TPAM molecule to prepare the acid-base blend membrane. Fig. 1 illustrated a possible proton transportations mechanism for the SPEEK/TPAM hybrid membrane. The acid-base interaction of hydrogen bonding between TPAM and SPEEK built an effective proton channel, promoting the proton crossover the hybrid membrane. The membrane roughness from the wrinkles and grooves of TPAM block the transportation of vanadium ions. ${ }^{45}$
Fig. 2(a-d) showed the cross-section morphology of pristine SPEEK membrane, SPEEK/TPAM (S/TPAM) membranes. In Fig. 2(a), the cross-section morphology of the pristine SPEEK membrane exhibited a smooth surface, while the hybrid membrane exhibited a relatively rough morphology in Fig. 2(b). The increased roughness is originated from the acidbase interaction. ${ }^{46}$ In Fig. 2(b), no cluster or aggregation appears, which meant that the TPAM molecule was welldistributed into the SPEEK matrix. However, the morphologies of S/TPAM-2\% and S/TPAM-5\% did not disperse as uniformly as S/TPAM-1\%, some cluster and aggregation were observed in the membranes. XPS spectra of the S/TPAM-1\% membrane was shown in Fig. 3. The peak of the N1s demonstrated that the TPAM was successfully doped into the SPEEK membrane. ${ }^{47}$

\subsection{Physicochemical properties}

The physicochemical properties of Nafion115, SPEEK membrane and S/TPAM membrane with different loadings were listed in Table 1. As shown in the list, the water uptake increased $\left(W_{\mathrm{U}}\right)$, the swelling ratio $\left(S_{\mathrm{R}}\right)$ and IEC decreased with the TPAM addition. This was possible attributed to the TPAM consumed the $\mathrm{SO}_{3} \mathrm{H}$ groups of SPEEK due to acid-base interaction. $^{48}$

Moreover, because of the proton channel built by SPEEK and TPAM, the proton conductivity of the blend membrane was higher than the pristine membrane. However, the conductivity of membranes decreased with the increase of the TPAM content. It could be ascribed to some cluster and aggregation

Table 1 The physicochemical property of Nafion 115 , SPEEK and S/TPAM membrane with $1 \%, 2 \%$ and $5 \%$ loading

\begin{tabular}{|c|c|c|c|c|c|c|c|}
\hline Sample & $\begin{array}{l}\text { Thickness } \\
(\mu \mathrm{m})\end{array}$ & $W_{\mathrm{U}}(\%)$ & $S_{\mathrm{R}}(\%)$ & $\begin{array}{l}\text { IEC } \\
\left(\mathrm{mmol} \mathrm{g}^{-1}\right)\end{array}$ & $\begin{array}{l}\text { Proton conductivity } \\
\left(\mathrm{S} \mathrm{cm}^{-1}\right)\end{array}$ & $\begin{array}{l}\mathrm{VO}^{2+} \text { permeability } \\
\left(10^{-7} \mathrm{~cm}^{2} \mathrm{~min}^{-1}\right)\end{array}$ & $\begin{array}{l}\text { Selectivity }\left(10^{4}\right. \\
\left.\mathrm{S} \mathrm{min} \mathrm{cm}^{-3}\right)\end{array}$ \\
\hline Nafion115 & 150 & 28.2 & 26.8 & 0.97 & 0.125 & 41.31 & 3.03 \\
\hline SPEEK & 115 & 36.8 & 16.4 & 1.64 & 0.061 & 3.56 & 17.13 \\
\hline S/TPAM-1\% & 108 & 39.3 & 13.7 & 1.55 & 0.070 & 3.04 & 23.02 \\
\hline S/TPAM-2\% & 98 & 38.7 & 14.2 & 1.42 & 0.064 & 3.23 & 19.81 \\
\hline S/TPAM-5\% & 118 & 39.5 & 15.6 & 1.13 & 0.063 & 6.56 & 9.60 \\
\hline
\end{tabular}
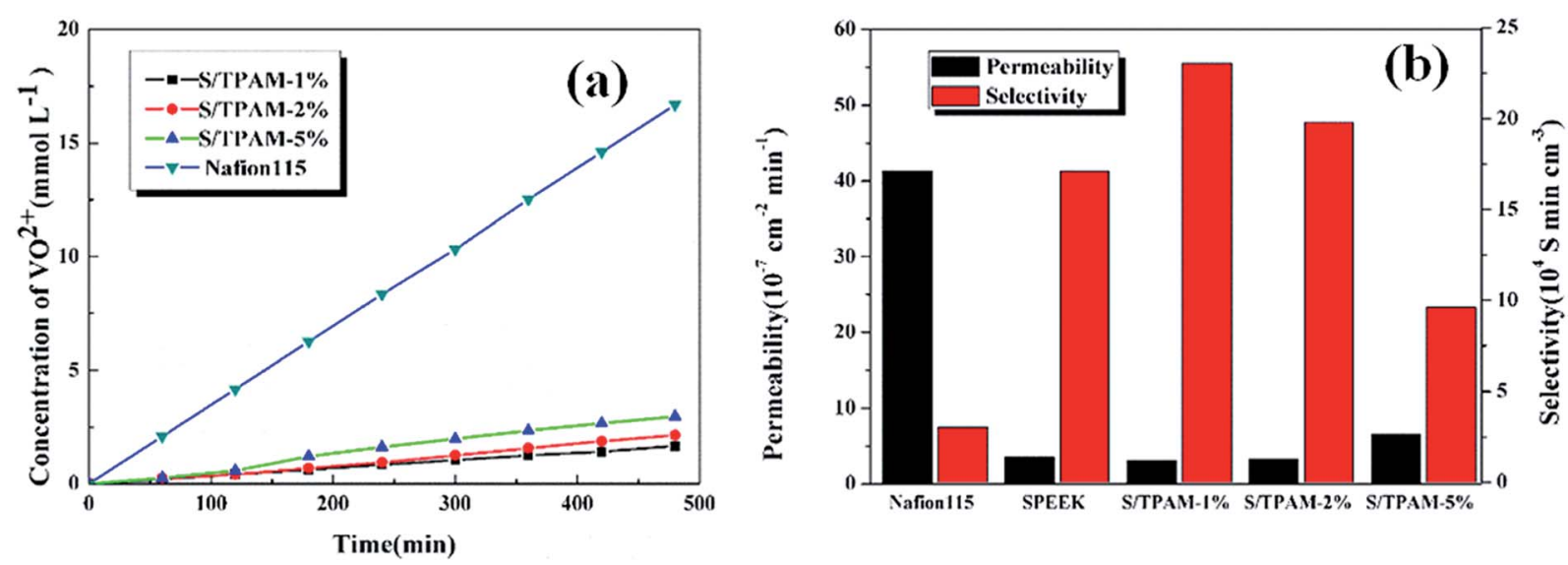

Fig. $4 \mathrm{VO}^{2+}$ permeability (a) and ion selectivity (b) of Nafion115 and S/TPAM membrane with different loading. 


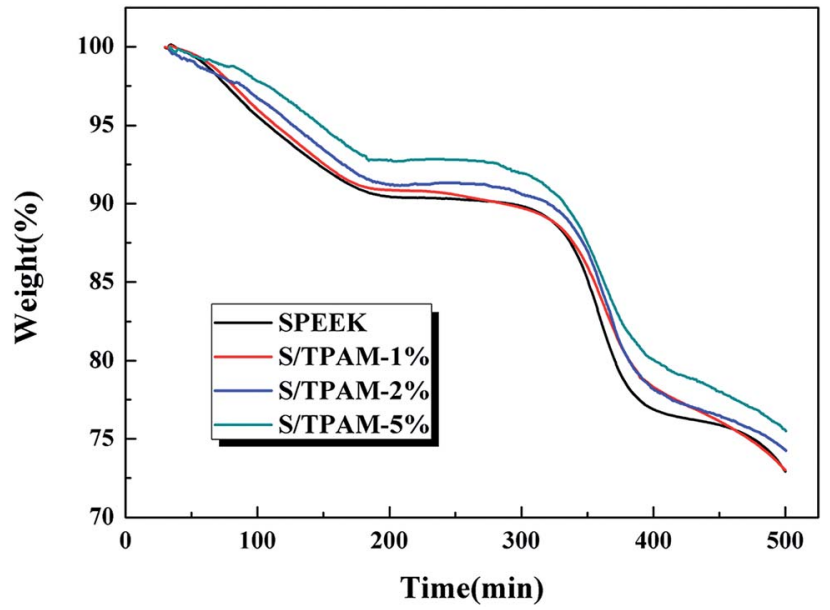

Fig. 5 The TGA curves of SPEEK and S/TPAM-1\%, S/TPAM- $2 \%$ and S/ TPAM-5\%.

Table 2 Chemical stability of Nafion115, SPEEK and S/TPAM-1\%

\begin{tabular}{ll}
\hline Sample & Weight loss (\%) \\
\hline Nafion115 & 2.4 \\
SPEEK & 6.2 \\
S/TPAM-1\% & 3.8
\end{tabular}

appearing in S/TPAM-2\% and S/TPAM-5\% influenced proton transportation in the SPEEK matrix. ${ }^{49}$

\subsection{Vanadium permeability and selectivity}

The vanadium permeability and selectivity were the significant properties of PEM applied in VRFB. PEM with high $\mathrm{VO}^{2+}$ permeability led to low coulombic efficiency, high rate of selfdischarge and capacity reduction of VRFB. ${ }^{50}$

As shown in Fig. 4(a), S/TPAM blend membranes exhibited much lower $\mathrm{VO}^{2+}$ permeation than Nafion115 membrane. It was considered as the result of the lower SR of the blend membrane compared with Nafion115 membrane. The existence of ion clusters caused the larger water channel, which led to higher SR

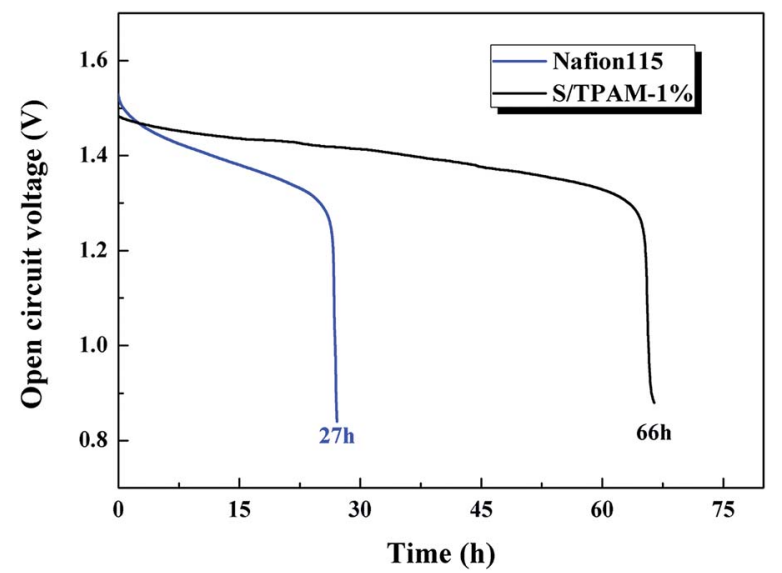

Fig. 6 Self-discharge curves of the VRFB with Nafion115 and S/TPAM-1\%.

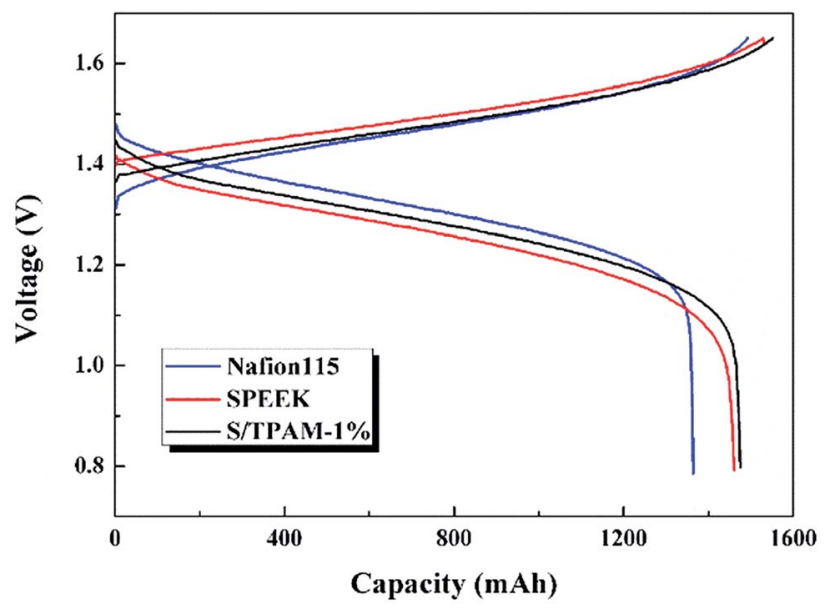

Fig. 7 Charge-discharge curves of the cell with Nafion115, SPEEK and S/TPAM- $1 \%$ at $60 \mathrm{~mA} \mathrm{~cm}^{-2}$.

of Nafion115 membrane. ${ }^{51}$ Nevertheless, when increasing TPAM content, vanadium permeability of the hybrid membrane also increased significantly. It was because the cluster and aggregation appearing in S/TPAM-2\% and S/TPAM-5\% increased the water channel and led the transportation of $\mathrm{VO}^{2+}$.

Ion selectivity was a comprehensive factor to predict the performance of PEM applied in VRFB. As in Fig. 4(b), the S/ TPAM-1\% membrane presented the highest selectivity (2.33 $\left.\times 10^{5} \mathrm{~S} \min \mathrm{cm}^{-3}\right)$, which was much higher than the

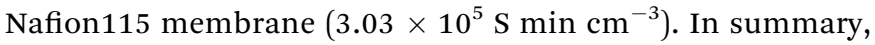
the S/TPAM-1\% membrane possessed the best physicochemical properties among other membranes and it can be utilized in VRFB.

\subsection{Thermogravimetric analysis}

Fig. 5 displayed the TGA curves of SPEEK, S/TPAM-1\%, S/TPAM$2 \%$ and S/TPAM-5\%. All the membranes presented two steps of thermal degradation. The first mass lost at $320^{\circ} \mathrm{C}$ was attributed to the degradation of sulfonated groups in SPEEK, while the

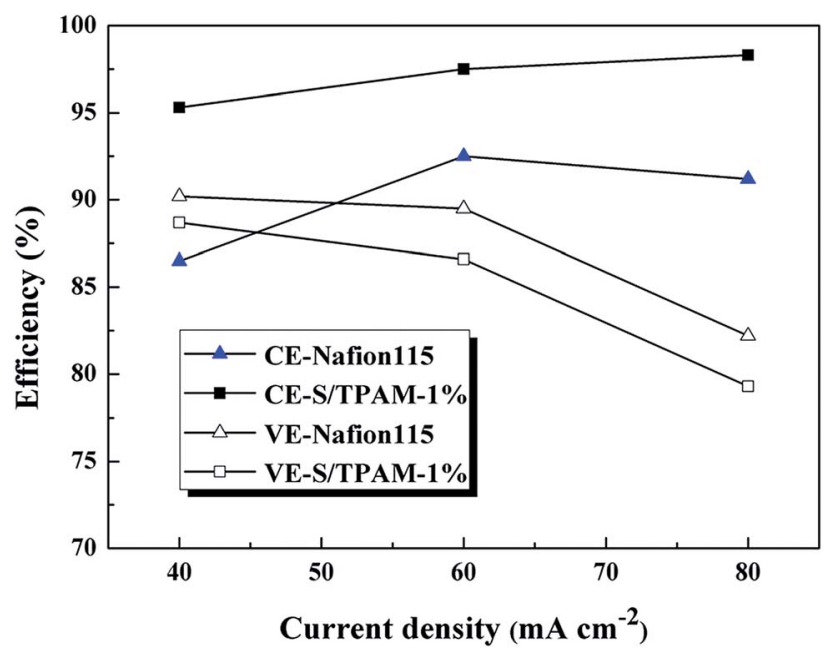

Fig. 8 CE and VE of VRFB with Nafion 115 and S/TPAM-1\% membranes at constant current densities from 40 to $80 \mathrm{~mA} \mathrm{~cm}^{-2}$. 
second mass lost occurring at $470{ }^{\circ} \mathrm{C}$ was owing to the decomposition of SPEEK polymer backbones. ${ }^{52}$ We observed that the hybrid membranes exhibited lower mass loss than the mass loss of the pristine membrane from $320{ }^{\circ} \mathrm{C}$ to $370{ }^{\circ} \mathrm{C}$, and the hybrid membranes showed better thermal stability with the increase of TPAM. Owing to the acid-base interaction between sulfonated groups and amine groups, a part of the sulfonated groups degraded at a higher temperature. ${ }^{53}$

\subsection{Chemical stability}

As listed in Table 2. Nafion115 showed the lowest weight loss owing to its molecular structure of perfluorosulfonic acid which exhibited the outstanding chemical stability. S/TPAM$1 \%$ membrane showed better stability than pristine SPEEK, it is attributed to the acid-base interactions between sulfonic groups of SPEEK and TPA. However, the weight loss of the hybrid membrane was still higher than that of Nafion115. The strategy to enhance the chemical stability of SPEEK needed to be further investigated.

\subsection{VRFB single cell test}

Because of the excellent selectivity, S/TPAM-1\% membrane was expected to be achieved in VRFB. Therefore, S/TPAM-1\% membrane was utilized in the VRFB single cell test. The selfdischarge curves of VRFB is illustrated in Fig. 6. The time of the open circuit voltage of VRFB with S/TPAM-1\% decay to $0.8 \mathrm{~V}$ was $66 \mathrm{~h}$, which is much longer than the self-discharge time of VRFB with Nafion115 (27 h). It is as the result of the vanadium permeability test.

Fig. 7 presented the charge-discharge curves of the cell with Nafion115, SPEEK and S/TPAM-1\% membrane at $60 \mathrm{~mA} \mathrm{~cm}^{-2}$. Due to different proton conductivities of diverse membranes, the average charge voltage of VRFB had an order of SPEEK > S/TPAM > Nafion115, while the average discharge voltage of the cell had an order of Nafion115 > S/TPAM > SPEEK. Furthermore, S/TPAM-1\% demonstrated higher charge capacity and higher discharge capacity than SPEEK and Nafion115 membrane, proving the superior balance between conductivity and vanadium permeability.

The efficiency of VRFB with Nafion115 and S/TPAM-1\% membranes at constant current densities from 40 to $80 \mathrm{~mA} \mathrm{~cm}^{-2}$ were compared in Fig. 8. The CE of S/TPAM-1\% membrane increased at the higher current density, while the CE of Nafion115 decreased at $80 \mathrm{~mA} \mathrm{~cm}^{-2}$. And the S/TPAM-1\% demonstrated much higher CE than Nafion115 at the same current density. The VE of VRFB with both two membranes decreased at the higher current density. The S/TPAM-1\% showed lower VE than Nafion115 at the same current density. The VRFB
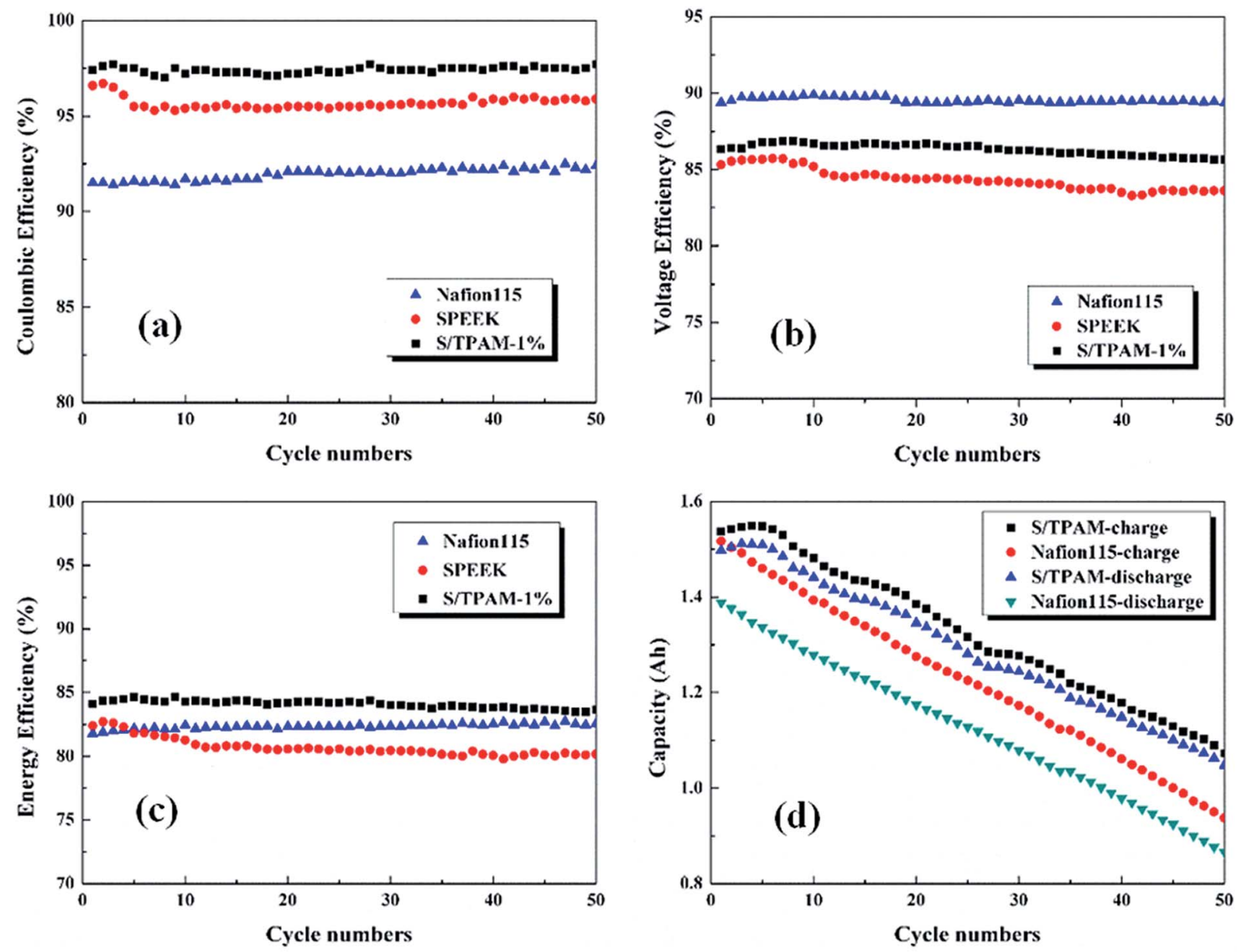

Fig. 9 The cycling test of VRFB with Nafion115, SPEEK and S/TPAM-1\% membrane at $60 \mathrm{~mA} \mathrm{~cm}{ }^{-2}$. 
with S/TPAM-1\% had the better rate performance than VRFB with Nafion115 at constant current densities from 40 to $80 \mathrm{~mA} \mathrm{~cm}{ }^{-2}$.

The cycling performance of diverse membranes was explored at the current density of $60 \mathrm{~mA} \mathrm{~cm}{ }^{-2}$, which was revealed in Fig. 9. As shown in Fig. 9(a), S/TPAM-1\% had the highest CE up to $97.5 \%$ among the tested membranes. It was a result of the acid-base interaction between TPAM and sulfonated groups, and this interaction reduced the vanadium crossover. The lowest CE of Nafion115 (92.5\%) membrane was caused by the large water channel and high swelling ratio. However, Nafion115 membrane possessed the higher VE (89.5\%) than S/ TPAM-1\% (86.6\%) and SPEEK (84.6\%) in Fig. 9(b). In addition, the VE of SPEEK appeared a downward trend with the increase of cycle number, but it was not the case on Nafion115 and the hybrid membrane. The reason was that the introduction of TPAM into SPEEK improved the chemical stability of membranes. EE, served as an indicator of energy conversion in the charge-discharge cycle, as shown in Fig. 9(c). The EE of S/ TPAM-1\% (83.8\%) was still higher than the Nafion115 (82.3\%) and SPEEK $(80.7 \%)$ membrane. It indicated the outstanding battery performance of the hybrid membrane, which was derived from a better balance between high conductivity and low vanadium cross-mixing. Moreover, the capacity reduction of the single cell was revealed in Fig. 9(d). Due to the great disparity of vanadium permeability, it was clear that the battery with S/TPAM-1\% had the advantages of both higher chargedischarge capacity and slower capacity decay than those with Nafion115 membrane. These results demonstrated the excellent cycling stability of S/TPAM-1\% membrane, that could promote the development of PEM for the long-life VRFB application.

\section{Conclusion}

A novel S/TPAM hybrid membrane was successfully prepared and first applied in VRFB. The introduction of TPAM can not only enhance the proton conductivity and chemical stability of SPEEK membrane with low DS but also, available, block the vanadium permeation. Furthermore, the higher CE, EE and charge-discharge capacity were obtained in VRFB single cell test with the S/TPAM-1\% membrane, compared with commonly used commercial Nafion115 membrane, the low-cost and easyprepared S/TPAM hybrid membrane could be a promising candidate for VRFB application.

\section{Conflicts of interest}

There are no conflicts to declare.

\section{Acknowledgements}

The work was supported by the National Natural Science Foundation of China (No. 51602209), the Provincial Nature Science Foundation of Sichuan (No. 2016GZ0423, 2017CC0017, 2018FZ0105) and the Technological Innovation Research and Development Project of Chengdu (2018-YF05-01409-GX) and the Fundamental Research Funds for the Central Universities (No. YJ201746, 2018SCUH0025).

\section{References}

$1 \mathrm{X}$. L. Zhou, et al., Critical transport issues for improving the performance of aqueous redox flow batteries, J. Power Sources, 2017, 339, 1-12.

2 X. L. Zhou, et al., Performance of a vanadium redox flow battery with a VANADion membrane, Appl. Energy, 2016, 180, 353-359.

3 M. Skyllas-Kazacos, et al., Progress in Flow Battery Research and Development, J. Electrochem. Soc., 2011, 158(8), R55R79.

4 A. Cunha, et al., Vanadium redox flow batteries: a technology review, Int. J. Energy Res., 2015, 39(7), 889-918.

5 C. Ding, et al., Vanadium Flow Battery for Energy Storage: Prospects and Challenges, J. Phys. Chem. Lett., 2013, 4(8), 1281-1294.

6 B. Schwenzer, et al., Membrane Development for Vanadium Redox Flow Batteries, Chemsuschem, 2011, 4(10), 1388-1406.

7 D. W. Shin, M. D. Guiver and Y. M. Lee, Hydrocarbon-Based Polymer Electrolyte Membranes: Importance of Morphology on Ion Transport and Membrane Stability, Chem. Rev., 2017, 117(6), 4759-4805.

$8 \mathrm{X}$. Li, et al., Ion exchange membranes for vanadium redox flow battery (VRB) applications, Energy Environ. Sci., 2011, 4(4), 1147-1160.

9 M. Ulaganathan, et al., Recent Advancements in AllVanadium Redox Flow Batteries, Adv. Mater. Interfaces, 2016, 3(1), 1500309.

10 B. Jiang, et al., A comparative study of Nafion series membranes for vanadium redox flow batteries, J. Membr. Sci., 2016, 510, 18-26.

11 C. Sun, et al., Investigations on transfer of water and vanadium ions across Nafion membrane in an operating vanadium redox flow battery, J. Power Sources, 2010, 195(3), 890-897.

$12 \mathrm{~W}$. Wei, et al., Poly(tetrafluoroethylene) reinforced sulfonated poly(ether ether ketone) membranes for vanadium redox flow battery application, J. Power Sources, 2012, 208, 421-425.

13 Z. Mai, et al., Nafion/polyvinylidene fluoride blend membranes with improved ion selectivity for vanadium redox flow battery application, J. Power Sources, 2011, 196(13), 5737-5741.

$14 \mathrm{X}$. Ling, et al., Preparation and characterization of sulfonated poly(ether sulfone)/sulfonated poly(ether ether ketone) blend membrane for vanadium redox flow battery, J. Membr. Sci., 2012, 415-416, 306-312.

$15 \mathrm{~J}$. Pan, et al., Layered zirconium phosphate sulfophenylphosphonates reinforced sulfonated poly (fluorenyl ether ketone) hybrid membranes with high proton conductivity and low vanadium ion permeability, $J$. Membr. Sci., 2013, 443, 19-27.

16 S. Winardi, et al., Sulfonated poly (ether ether ketone)-based proton exchange membranes for vanadium redox battery applications, J. Membr. Sci., 2014, 450, 313-322. 
17 Z. Jiang, X. Zhao and A. Manthiram, Sulfonated poly(ether ether ketone) membranes with sulfonated graphene oxide fillers for direct methanol fuel cells, Int. J. Hydrogen Energy, 2013, 38(14), 5875-5884.

$18 \mathrm{H}$. Zhang, et al., Crosslinkable sulfonated poly (diallylbisphenol ether ether ketone) membranes for vanadium redox flow battery application, J. Power Sources, 2012, 217, 309-315.

19 F. Zhai, et al., Synthesis and properties of novel sulfonated polyimide membranes for direct methanol fuel cell application, J. Membr. Sci., 2007, 296(1-2), 102-109.

20 S. Peng, et al., Polybenzimidazole membranes with nanophase-separated structure induced by non-ionic hydrophilic side chains for vanadium flow batteries, $J$. Mater. Chem. A, 2018, 6(9), 3895-3905.

$21 \mathrm{~S}$. Kim, et al., Cycling performance and efficiency of sulfonated poly(sulfone) membranes in vanadium redox flow batteries, Electrochem. Commun., 2010, 12(11), 16501653.

22 C. Minke and T. Turek, Economics of vanadium redox flow battery membranes, J. Power Sources, 2015, 286, 247-257.

$23 \mathrm{~J}$. Xi, et al., Effect of degree of sulfonation and casting solvent on sulfonated poly(ether ether ketone) membrane for vanadium redox flow battery, J. Power Sources, 2015, 285, 195-204.

$24 \mathrm{~J}$. Zhang, et al., Sulfonated poly(ether ether ketone)/ $/ \mathrm{TiO}_{2}$ double-deck membrane for vanadium redox flow battery application, J. Electroanal. Chem., 2016, 783, 76-81.

25 Y. Ji, Z. Y. Tay and S. F. Y. Li, Highly selective sulfonated poly(ether ether ketone)/titanium oxide composite membranes for vanadium redox flow batteries, J. Membr. Sci., 2017, 539, 197-205.

$26 \mathrm{~J} . \mathrm{Xi}$, et al., Nafion/ $\mathrm{SiO}_{2}$ hybrid membrane for vanadium redox flow battery, J. Power Sources, 2007, 166(2), 531-536.

27 P. Salarizadeh, M. Javanbakht and S. Pourmahdian, Enhancing the performance of SPEEK polymer electrolyte membranes using functionalized $\mathrm{TiO}_{2}$ nanoparticles with proton hopping sites, RSC Adv., 2017, 7(14), 8303-8313.

28 Z. Li, et al., Properties Investigation of Sulfonated Poly(ether ether ketone)/Polyacrylonitrile Acid-Base Blend Membrane for Vanadium Redox Flow Battery Application, ACS Appl. Mater. Interfaces, 2014, 6(21), 18885-18893.

$29 \mathrm{Z}$. Li, et al., Preparation and characterization of sulfonated poly(ether ether ketone)/poly(vinylidene fluoride) blend membrane for vanadium redox flow battery application, $J$. Power Sources, 2013, 237, 132-140.

30 F. Wang, et al., Novel sulfonated poly(ether ether ketone)/ oxidized g- $\mathrm{C}_{3} \mathrm{~N}_{4}$ composite membrane for vanadium redox flow battery applications, J. Electroanal. Chem., 2017, 797, 107-112.

31 Q. Che and J. Yue, Polymerized imidazolium ionic liquids crosslinking sulfonated poly(ether ether ketone) (SPEEK) for high-temperature proton exchange membrane, $R S C$ Adv., 2016, 6(113), 111729-111738.

32 G. Wang, et al., Sulfonated poly(ether ether ketone)/ poly(vinylidene fluoride)/graphene composite membrane for a vanadium redox flow battery, $J$. Solid State Electrochem., 2017, 21(4), 1185-1194.

33 L. H. Yu and J. Y. Xi, Durable and Efficient PTFE Sandwiched SPEEK Membrane for Vanadium Flow Batteries, ACS Appl. Mater. Interfaces, 2016, 8(36), 23425-23430.

$34 \mathrm{~J}$. Xi, W. Dai and L. Yu, Polydopamine coated SPEEK membrane for a vanadium redox flow battery, RSC Adv., 2015, 5(42), 33400-33406.

$35 \mathrm{X}$. Yan, et al., A novel imidazolium-based amphoteric membrane for high-performance vanadium redox flow battery, J. Membr. Sci., 2017, 544, 98-107.

36 P. Agarwala and D. Kabra, A review on triphenylamine (TPA) based organic hole transport materials (HTMs) for dye sensitized solar cells (DSSCs) and perovskite solar cells (PSCs): evolution and molecular engineering, J. Mater. Chem. A, 2017, 5(4), 1348-1373.

$37 \mathrm{~K}$. Zhang, et al., A thermally and electrochemically stable organic hole-transporting material with an adamantane central core and triarylamine moieties, Synth. Met., 2012, 162(5-6), 490-496.

38 R. Lei, et al., Sulfonated polyimides containing 1,2,4-triazole groups for proton exchange membranes, Chin. J. Polym. Sci., 2014, 32(7), 941-952.

39 J. Kerres and A. Ullrich, Synthesis of novel engineering polymers containing basic side groups and their application in acid-base polymer blend membranes, Sep. Purif. Technol., 2001, 22-3(1-3), 1-15.

$40 \mathrm{~J}$. Zeng, et al., Studies on polypyrrole modified nafion membrane for vanadium redox flow battery, Electrochem. Commun., 2008, 10(3), 372-375.

41 L. Li, et al., Effect of Sulfonated Poly(ether ether ketone) Membranes with Different Sulfonation Degrees on the Performance of Vanadium Redox Flow Battery, Acta Chim. Sin., 2009, 67(24), 2785-2790.

42 Y. Zhang, et al., Sulfonated poly(ether ether ketone)/ poly(vinylidene fluoride)/tungstophosphoric acid membrane for vanadium redox flow battery application, High Perform. Polym., 2016, 28(6), 735-740.

$43 \mathrm{Z}$. Li, et al., Characterization of sulfonated poly(ether ether ketone)/poly(vinylidene fluoride-co-hexafluoropropylene) composite membrane for vanadium redox flow battery application, J. Power Sources, 2014, 272, 427-435.

44 Y. A. Gandomi, D. S. Aaron and M. M. Mench, Coupled Membrane Transport Parameters for Ionic Species in AllVanadium Redox Flow Batteries, Electrochim. Acta, 2016, 218, 174-190.

45 R. Niu, et al., Novel graphitic carbon nitride nanosheets/ sulfonated poly(ether ether ketone) acid-base hybrid membrane for vanadium redox flow battery, J. Membr. Sci., 2017, 525, 220-228.

46 Y. Zhang, et al., Sulfonated poly(ether ether ketone)-based hybrid membranes containing polydopamine-decorated multiwalled carbon nanotubes with acid-base pairs for all vanadium redox flow battery, J. Membr. Sci., 2018, 564, 916-925.

47 L. Cao, et al., Novel sulfonated polyimide/zwitterionic polymer-functionalized graphene oxide hybrid membranes 
for vanadium redox flow battery, J. Power Sources, 2015, 299, 255-264.

48 L. Kong, et al., A sulfonated poly(ether ether ketone)/aminefunctionalized graphene oxide hybrid membrane for vanadium redox flow batteries, RSC Adv., 2016, 6(102), 100262-100270.

49 L. Cao, et al., Novel acid-base hybrid membrane based on amine-functionalized reduced graphene oxide and sulfonated polyimide for vanadium redox flow battery, Electrochim. Acta, 2015, 158, 24-34.

50 X. Teng, et al., PTFE/SPEEK/PDDA/PSS composite membrane for vanadium redox flow battery application, J. Mater. Sci., 2018, 53(7), 5204-5215.
51 B. Jiang, et al., Insights into the Impact of the Nafion Membrane Pretreatment Process on Vanadium Flow Battery Performance, ACS Appl. Mater. Interfaces, 2016, 8(19), 12228-12238.

52 J. Antonio Asensio, E. M. Sanchez and P. Gomez-Romero, Proton-conducting membranes based on benzimidazole polymers for high-temperature PEM fuel cells. A chemical quest, Chem. Soc. Rev., 2010, 39(8), 3210-3239.

53 D. Chen, et al., Advanced acid-base blend ion exchange membranes with high performance for vanadium flow battery application, J. Membr. Sci., 2018, 553, 25-31. 